\title{
¿PARA QUÉ POESÍA EN TIEMPOS DE DESIGUALDAD? IMAGINACIÓN, MEMORIA Y POLÍTICA DE LA ESCRITURA EN EL CONTEXTO DE LA “CULTURA DE MERCADO” EN EL CHILE DEL BICENTENARIO
}

Why poetry in times of inequality?

Imagination, memory and politics of writing

in the context of a "market culture" in the Chile of the Bicentennial

Sergio Mansilla Torres*

Resumen

Una importante zona de la poesía chilena pareciera que ha sustituido el auténtico lirismo por una hipertrofia de lo metapoético que se correlaciona con un alto grado de especialización de la escritura. Especialización que acontece menos como formas de (re)escrituras vanguardistas o postvanguardistas, y más como consecuencia sociocultural de la cerrazón del horizonte histórico y político, cerrazón que hace posible y sustentable un modo poético de imaginar sin una verdadera referencialidad. Por el contrario, escrituras cuya retoricidad transmuta memorias culturales de una cierta comunidad territorializada, trabajan en función de asegurar que la poesía no sea un fin en sí mismo, sino un medio para leer/escribir de una manera "fuerte" la historia, el mundo.

Palabras clave: Poesía chilena, memoria poética, poesía de la transición, historización de la poesía.

\section{Abstract}

A significant portion of chilean poetry seems to have substituted authentic liricism for a hypertrophy of the metapoetical, which correlates with the high degree of specialization of writing. This specialization occurs less as forms of vanguard or post-vanguard (re)writings, and more as a sociocultural consequence of the clouding of the political and historical horizon; a clouding that makes a poetic imagination without reference to reality possible and sustainable. On the contrary, writings whose rhetoric transmutes cultural memories of a specific territorialized community, function in order to assure that the poetry not be the end in and of itself, but the medium through which to read/write "strongly" history, the world.

Key words: Chilean poetry, poetic memory, poetry of the transition, historization of poetry.

\section{A MODO DE INTRODUCCIÓN}

Quisiera poner en discusión algunas tesis generales sobre la situación de la poesía chilena en el contexto de un país cuya dominante cultural (aquélla que se disemina desde las estructuras de poder hasta ahora hegemónicas) se conforma, diciéndolo en terminología de Cárcamo-Huechante, como "tramas 


\section{Sergio Mansilla Torres}

de mercado" que sustentan un modelo de desarrollo y de sociedad fundado en la privatización extrema de los aparatos productivos y de servicios y en la consiguiente competencia del uno contra el otro por nichos de mercado. ${ }^{1}$ Aunque decir tesis sea, en realidad, un exceso. Se trata más bien de incitar a la discusión y a la reflexión acerca de la situación de la poesía chilena en una época de pérdida de eficacia de utopías en disenso que, por lo menos en Chile y hasta los años de 1970, delineaban los campos ideológicos fundamentales (izquierdas y derechas, no obstante los matices varios) y sus respectivas praxis de una manera relativamente clara; incitación que arranca de afirmaciones que, creemos, dan cuenta de ciertos dilemas en los que la poesía chilena actual se encuentra atrapada en lo que concierne a su relación con la historia, con el campo político, con las identidades culturales, con el orden de las relaciones de poder que sostienen una cultura y una sociedad, como la del Chile de hoy, en el que el "ninguneo" de proyectos políticos alternativos (cualquiera que no sea el del neoliberalismo, desde luego) y la tendencia a la borradura de la memoria histórica, es moneda corriente. Se trata, en rigor, de dilemas que tienen que ver con la eficacia política y estética de lenguajes que una sociedad, que aún no se ha liberado del shock de la dictadura del mercado y la economía, puede o no puede articular.

Como toda aproximación general, ésta es parcial e interesada. Parcial en la medida en que nuestro propósito principal no es sino perfilar las líneas gruesas límites de lo que podríamos llamar el campo textual-ideológico de la poesía chilena, haciendo, por ahora, caso omiso de los muchos registros escriturales particulares que pueblan el gran tablado de la poesía escrita por autores chilenos, tanto dentro como fuera del país. ${ }^{2}$ La variedad de registros es

\footnotetext{
${ }^{1}$ Una de las tesis centrales que sostiene Cárcamo-Huechante se refiere a que la instalación del "libre mercado" como viga maestra del ordenamiento económico chileno a partir de fines de los años de 1970 se entrelaza, se hace una trama, con un "ajuste cultural" y un "giro simbólico" que, en su conjunto, generan condiciones favorables no sólo para la intervención fáctica en los procesos económicos y mercantiles orientada a consolidar el modelo neoliberal, sino $-\mathrm{y}$ es lo que importa para nuestra discusión - generan condiciones para imaginar y comprender la realidad material de la historia con conceptos e imágenes que difícilmente se escapan de estas "tramas de mercado". Obviamente, la "competencia por nichos de mercado", en la medida en que se van acrecentando los monopolios, se torna cada vez más simulacro de competencia, una trama discursiva de mercado.

${ }^{2}$ Dejo constancia de que en esta discusión no considero la poesía chilena escrita por autores radicados fuera de Chile. Reflexionar sobre poesía reciente de Chile escrita en el extranjero implicaría una dedicación exclusiva, dado el número de poetas, dispersión geográfica, condiciones culturales (o interculturales e interidiomáticas) propias, no comparables con la poesía escrita dentro de los límites domésticos de la nación. Hasta ahora no existe un censo confiable que sistematice nombres y obras de poetas chilenos en el extranjero; aunque, por cierto, autores como Oscar Hahn, Waldo Rojas, Javier Campos, Carlos Trujillo, Jorge Etcheverry, el mismo Efraín Barquero, Premio Nacional de Literatura 2008, que vive en Francia, son, entre otros, nombres que surgen rápidamente a la hora de hacer cualquier recuento de poetas chilenos radicados en tierras extranjeras.
} 


\section{¿Para qué poesía en tiempos de desigualdad?}

sin duda signo de vitalidad creativa; pero cuando esta variedad acontece como suma de compartimientos cuya eficacia socioliteraria queda librada al éxito competitivo del poeta y su entorno — como en gran medida está ocurriendo en Chile- quiere decir que "algo huele mal en Dinamarca": la poesía se ha vuelto más un campo de ofertas textuales que un genuino campo dialógico en el que las diversas escrituras tendrían que visibilizarse, con sus mutuas querellas y confluencias, en la centralidad cultural de la nación. Sospecho que la potencia que, hoy por hoy, en nuestro país exhibe la poesía de las memorias culturales territorializadas es un fenómeno cuyo combustible primero tiene que ver menos con el campo poético propiamente tal (diálogo y querellas entre estéticas) y mucho más con el conflicto político, cultural y aun económico de comunidades que han emprendido procesos de insubordinación cultural y discursiva, conducentes eventualmente a insubordinaciones políticas más de fondo.

Aproximación interesada en tanto se trata de una mirada personal en el exacto sentido del término, que responde a una particular sensibilidad, la mía en este caso, que se compromete con ciertas preferencias estéticas por sobre otras. No me resulta fácil, debo confesarlo, sobrellevar las lecturas de poesías neoconceptuales (permítaseme el término) cuyos lenguajes nos enfrentan a densas texturas de conceptos y alegorías en los que la realidad material del mundo aparece diluida en tramas de citas y referencias y relegada a un segundo orden de realidad. Como si el lenguaje por sí solo, sin sus referentes "duros" de realidad material extralingüística, bastara para producir una experiencia poética. En esto hay, qué duda cabe, muchos matices, y, por encima de preferencias personales, es obligación inexcusable reconocer el enorme aporte a la poesía moderna (no sólo a la chilena) de aquellas estéticas desterritorializadas, que fundan sus mundos líricos en tensar, hasta el límite a veces, la gramaticalidad y semanticidad del idioma en un gesto discursivo poderosamente metatextual.

\section{POESÍA DE LA TRANSICIÓN ¿O TRANSICIÓN DE LA POESÍA?}

En 1994, la Revista Acta Literaria de la Universidad de Concepción me publicó un artículo en el que me permití cuestionar, en algún grado, la visión que el poeta y crítico Eduardo Llanos Melussa tenía de la poesía chilena que para entonces se estaba escribiendo y publicando en el país (1994). Los juicios de Llanos, expresados en el prólogo de Los dominios perdidos - libro que contiene una muestra antológica de la poesía de Jorge Teillier - atestiguaban una visión sombría de parte del prologuista en torno a la poesía chilena de inicios de los años de 1990

En el caso de mi hornada (Llanos se refiere básicamente a la promoción de poetas nacidos entre 1950 y 1965), aunque ha producido obras que obviamente enriquecen el acervo poético nacional, creo que muestra como 


\section{Sergio Mansilla Torres}

promedio un nivel de oficio comparativamente bajo, que resulta dramático si se lo relaciona con los ambiciosos proyectos neofundacionales que animaban a algunos de ellos y que, hace un lustro o menos, se tenían por renovaciones indiscutibles. (...) Esta visión un tanto sombría (...) depende más del contexto histórico que de mi subjetividad (...). El problema es que la poesía que actualmente se está publicando en nuestra lengua es, como globalidad, inferior a la que surgió en los años sesenta, cuando campeaba una creatividad formidable por todos o casi todos los ámbitos de la cultura latinoamericana (Llanos, 10).

Mi contra argumento se basó en sostener que los poetas chilenos que no alcanzaron la madurez estética antes de 1973 o que nacieron a la vida literaria en la atmósfera de la represión y desmantelamiento de aquel estado más o menos benefactor que había socorrido de una manera $u$ otra a muchos poetas otorgándoles cargos diplomáticos, cátedras en universidades y/o en colegios prestigiosos; otorgándoles, digamos, una cierta protección institucional (aunque tal protección, precaria casi siempre pero protección al fin, dependía a menudo de la buena disposición de amigos o conocidos que oficiaban de autoridad en ámbitos públicos o semipúblicos). Digo, estos nuevos poetas del "contragolpe" tuvieron que formarse enfrentados a una situación de violencia dictatorial que, entre otras cosas, hizo trizas los puentes sociogeneracionales por los que con bastante fluidez había transitado la poesía chilena desde los tiempos de Pezoa Véliz y el joven Huidobro. Las difíciles condiciones políticas, ideológicas, socioculturales y económicas en las que vivieron, escribieron y leyeron los jóvenes poetas de la generación que Aristóteles España ha llamado $\mathrm{NN},{ }^{3}$ la ya aludida desarticulación de la institucionalidad literaria (sobre todo de aquella que se había venido consolidando en las universidades, financiadas entonces básicamente por el Estado), la censura que cayó como una inmensa nube oscura sobre el lenguaje y la imaginación, dieron paso a una tarea más colectiva que individual, más de coro que de solistas deslumbrantes.

Lo que en su momento fue una urgente necesidad de escribir una poesía cuyos lenguajes no se rindieran simplemente a la violencia dictatorial y a sus opresivos discursos de legitimación, se volvió un complejo desafío estético y político - aún en curso - que abrió la puerta a una historización radical de la imaginación poética chilena, la que se vio obligada a ensayar diversas posibilidades discursivas. Ya no se trataba de atrincherarse, sin más, en una escritura parasitariamente contraria a la contingencia represora pero tampoco era cuestión de ignorarla u obliterarla tras el biombo de un hipertextualismo

${ }^{3}$ Cfr., la antología Poesía chilena. Generación NN (1973-1991). Punta Arenas: La Pata de Liebre, 1993. En realidad el término "Generación NN" lo acuña Eduardo Llanos Melussa en 1984 durante el Primer Encuentro de Escritores Jóvenes de Chile, realizado en Santiago en dependencias de la Sociedad de Escritores de Chile. España, por cierto, hace suyo el término. 


\section{¿Para qué poesía en tiempos de desigualdad?}

esteticista y/o de las poéticas de los mundos personales "deshistorizados". Asimismo, no resultaba productivo adscribirse a la estética del vate poseedor de la Gran Palabra que la ofrece a sus lectores - a su pueblo, digamos - en un gesto de desprendimiento paternal, como un bien supremo garantizador de una visión trascendente y proféticamente iluminadora de la historia toda. Una totalizante negación irónica y radical de esta estética tampoco era el camino: la antipoesía parriana si tiene algo que decir después de 1973 no será por su estilo antipoético en un sentido restringidamente textual, sino por sus efectos de irrisión contra las solemnidades de los discursos de un poder antilibertario, entre los cuales "la poesía del tonto solemne" es uno más. Son éstos, a mi parecer, factores que incidieron de manera determinante en la emergencia de una rica pluralidad de registros poéticos y voces, ninguna de las cuales, sin embargo, ni siquiera la de Raúl Zurita ${ }^{4}$ - y en esto coincido con Llanos— 5 se erigió como "el gran poeta", la "gran revelación".

Como fuere, la poesía chilena cruzó, no sin pérdidas considerables, el campo minado de la dictadura y el terror institucionalizado. Y lo cruzó protegida por la armadura de la memoria poética de la historia y por el despliegue de subjetividades plurales que entran al ruedo de la escritura a través de sujetos líricos que se proyectan en una dirección que, si no es contraria, al menos tensa al inclusivo yo wihtmaniano propio de una cierta modernidad poética que viene del siglo XIX: aquélla sintonizada con una forma de modernidad política de corte liberal progresista que destilaba una inagotable confianza en el sí mismo. No es casual, por ejemplo, que la emergencia de la llamada poesía etnocultural, de base indígena o no - que a la fecha ha llegado a convertirse en una especie de movimiento de creación y crítica textual y cultural — es un fenómeno de legitimación de heterogeneidad

\footnotetext{
${ }^{4}$ Entiéndase: no se trata de restarle mérito a un poeta como Zurita (o como Juan Cámeron o Juan Luis Martínez, por nombrar a algunos del grupo original de Zurita del Café Cinema en Viña del Mar). Me refiero al hecho sociológico de que en los últimos 30 años, tiempo equivalente a una generación completa, no hay epónimos en la poesía chilena.

5 Me disculparán los lectores por esta, quizás, poco afortunada autorreferencia inicial. Pero, viene a cuento en la medida en que ese conato de discusión que sostuvimos Llanos y yo hace ya casi 19 años hoy podría verse como los escarceos iniciales de un problema que se me figura de importancia capital para la poesía chilena a la vuelta del Bicentenario de la República: ¿Para dónde va la lancha de la poesía chilena del siglo XXI? La pregunta, formulada en jerga marinera, tiene razón de ser si asumimos la sospecha de que en el Chile actual hay casi tantos poetas como habitantes, pero, a la hora de tamizar las escrituras en la estrecha criba de una estética que verdaderamente nos sorprenda por la complejidad de su simbolismo y, a la vez, por su comunicabilidad en el terreno del pensamiento y la emoción (y no por su hermetismo metapoético o metadiscursivo plagado, a menudo, de alegorías de un "malditismo" algo anacrónico a estas alturas), la muchedumbre de poetas se reduce tan drásticamente que, bien miradas las cosas, autorizaría a decir que los poetas en Chile no abundan, no obstante la impresión contraria que se tiene a primera vista.
} 


\section{Sergio Mansilla Torres}

de escrituras (y de culturas) que despega en la década de los años 80 y 90 del siglo XX, justo en un momento en que se hacía políticamente imprescindible hacer de la pluralidad y diferencia de sujetos, culturalmente situados, pivotes para insubordinar la imaginación contra la violenta homogeneización autoritaria. ${ }^{6}$ El otro modo de cruzar el campo minado del autoritarismo fue apelando a la estrategia de cuestionamiento de las convenciones poéticas y capacidades de significación y referencialidad del lenguaje, de manera que a menudo la poesía se volvió un ambivalente juego de afirmación/negación de la posibilidad misma de construir sentido con el lenguaje acerca de una realidad percibida como inestable, incierta, indecible, desprovista en cualquier caso de toda aura de ejemplaridad; gesto escritural que viene de esa constelación llamada Enrique Lihn y que adquiere, en los años 70-80, su formulación más radical en las provocativas escrituras de Juan Luis Martínez, Rodrigo Lira y, en menor medida, de Eugenia Brito, Elvira Hernández y Carmen Berenguer, por nombrar los autores(as) más visibles.

Esta "pluralidad de voces" pudo ser - como creo que en efecto lo fueuna respuesta necesaria en el campo de la poesía a los desafíos que se imponían en la etapa política de protestas y de represión de los años 1980; pluralidad que bien mirada acontece como una no despreciable forma de democratización discursiva en la medida en que la poesía deja de ser patrimonio del poeta "profesional", del poeta intelectual en condiciones de teorizar con brillantez sobre su propio quehacer poético (y también sobre el quehacer ajeno). La poesía se vuelve moneda corriente a disposición de presos políticos, de jóvenes airados que protestaban contra las estructuras dictatoriales reclamando por un país justo y libre. Dicho de otro modo, la poesía pasa a ser propiedad de cualquier persona en condiciones de escribir versos o, incluso, de escribir simples divagaciones poéticas sin más pretensión que ser registros de estados emocionales. En una situación política de censura explícita, decir algo que violente la censura, por pueril que pueda parecer lo que se diga, constituye en sí mismo un acto de resistencia política. ${ }^{7}$ Y como esta

\footnotetext{
${ }^{6}$ Desde luego, la diversidad de sujetos líricos no sólo se hizo visible en la poesía etnocultural. La emergencia de poesía de mujeres (que se construye sobre la base de una cierta conciencia insubordinada de género) así como escrituras con marcas territoriales (poesía del sur, por ejemplo), fueron en los años 80-90 categorías entre descriptivas y performativas que surgen de la necesidad última de imaginar un país plural otorgando voz a sujetos históricamente fuera de la centralidad de la nación. Aunque este gesto democrático y liberador no tenga, en muchos casos, más realidad que la realidad de la ficción poética.

${ }^{7}$ En los años de 1980 libros como Poesía prisionera. Escritura de cinco mujeres encarceladas. Antología y prólogo de Bruno Serrano (Santiago: Literatura Alternativa, 1988), eran objeto de respetuosas recepciones en el ambiente de la poesía y en el mundo político contra la dictadura por el valor testimonial de los versos y por su respectivo efecto denunciatorio, quedando en segunda línea una lectura propiamente estética. En 2009, libros como éstos son una rareza. ¿Será porque se acabaron las situaciones de urgencia en la larga transición pactada a la
} 


\section{¿Para qué poesía en tiempos de desigualdad?}

resistencia, dado el escenario de violencia institucional e implacable censura, no puede presentarse con total desembozo so pena de la aniquilación física de las voces disonantes. Así, el campo estético pasa a ser el espacio de cobijo de muchos discursos que, pudiendo ser artísticamente precarios, sí movilizan la imaginación y la emocionalidad contra un poder que se lo representa (y se lo vive en consecuencia) como intolerablemente opresivo.

Sin embargo, este pluralismo poético, ahora en el escenario del período democrático de la transición pactada (desde 1990 a la fecha), pasa a ser pretexto y coartada. Pretexto que da pie para legitimar una cierta pluralidad de voces de manera tal que se cancela la necesidad de distinguir entre aquellas escrituras que de veras comunican una cierta narrativa del yo a través de la cual el mundo se muestra con una genuina extrañeza en el orden de lo imaginario y lo simbólico. Me refiero a escrituras que proveen - como diría Seamus Heaney al referirse sobre la felicidad y la poesía en el apartado "La utilidad del arte" (en línea) - de "un interior, una zona de protección de los sentimientos" y que se diferencian de aquellas otras que adolecen de una cierta hipertrofia de retoricidad, tanto que la textualidad en sí mima se vuelve o bien caja de resonancia de estereotipos ya desgastados o bien un dechado de formalizaciones más o menos "surrealistas" que da paso a una suerte de hermetismo semántico que destila a veces derrota, imposibilidad de imaginar otra realidad que no sea el ruinoso "fin de la historia". Pretexto, en suma, para quedarse tranquilo ante la heterogeneidad de un vocerío presuntamente restituyente de lo diverso y justificarlo con apelaciones a sospechosos postmodernismos que explican todo y nada.

Una coartada en la medida que probaría que ni el poeta ni el crítico estarían obligados a emitir juicios, en un ámbito público y con alcances rigurosamente políticos, sobre la calidad estética de la poesía ¿Para qué pontificar si la poesía la hacen todos, cada uno según sus necesidades, y si, además, se asume que es el lector el que en última instancia decidirá final y libremente con qué escritura se identifica? Después de todo, el mercado por sí solo también podría regular la oferta discursiva, haciendo que se produzcan, por ejemplo, nichos de circulación simbólica relativamente restringidos, pequeñas poblaciones de consumidores cautivos de metáforas que reiteren hasta el paroxismo una cierta estructura de sensibilidad particular (de indígenas, de mujeres, de homosexuales, de tribus urbanas, por mencionar algunos nichos de imaginación y de escritura). Cuando

democracia? No es tan así, sin embargo. Un libro como Poesía de Villa Francia. Anidarás en el bosque de las aves que somos (2008) es la evidencia que la poesía "urgente" que atestigua indecibles marginalidades sistémicas tiene todavía mucho que decir, más si éstas acontecen en democracia en un Chile que oficialmente proclama estar a las puertas de la condición de "país desarrollado". 


\section{Sergio Mansilla Torres}

todo vale, nada exige pronunciamientos sobre la valencia de una cosa en relación con otra más allá del estrecho ámbito de la funcionalidad inmediata: estamos en una democracia sin más horizontes teleológicos que acrecentar la competitividad y el individualismo, y la literatura no escapa a esta dominante políticocultural. Lo malo de no establecer jerarquías y límites en el campo poético es que, como en el tango "Cambalache", desgraciadamente a la larga "da lo mismo ser un burro que un gran profesor".

"Como condición general, el pluralismo tiende a absorber la discusión lo que no equivale a decir que no promueva antagonismos de todo tipo". Así describe Hal Foster la indiferenciada espesura del arte actual en la que "ningún estilo, o siquiera moda de arte, es dominante y ninguna posición crítica es ortodoxa". Y agrega: "porque en un estado de pluralismo se tiende a dispersar, y a volver así impotentes, el arte y la crítica" (1, en línea). El juicio de Foster, que emite sobre la "condición postmoderna" del arte primer mundista que se ha venido haciendo desde los años 70 hacia acá, es transferible al panorama de la poesía chilena actual, al menos a aquella poesía escrita por autores finiseculares. Lo que otrora fue el reclamo por una radical democracia escritural se ha vuelto una práctica sociocultural de producción poética corrompida: se conserva el rigor autocrítico pero sin demasiado soporte dialógico; se respeta a los autores paradigmáticos de la poesía chilena moderna, pero no estoy seguro de que sean ellos leídos con la finalidad de comprender actualizadamente los aciertos y fisuras de sus mundos poéticos, $\mathrm{o}$, si se prefiere, decodificar la validez en el mundo de hoy de los signos de una poesía que no sólo, creo yo —al menos - instaló determinadas poéticas en tanto particulares estilos de escritura sino que, sobre todo, creó narrativas de subjetividades que, para bien o para mal, sí tenían grandes relatos que contar sobre el decurso de nuestras vidas. Nuestro tiempo, sin duda, no renuncia a la búsqueda de originalidad en la poesía, algo que se hace patente incluso en el acto mismo de negarla; aunque tal búsqueda, en la práctica, se alimente a menudo de un "simbolismo" a la manera de un Rimbaud leído como el eterno enfant terrible que escupe todos los malestares de una historia huérfana de verdaderas revoluciones (o incluso huérfana de imágenes de revoluciones) o de un Baudelaire que siempre viene en socorro de modos de imaginar que no pueden concebir el mundo sino como un campo poblado de irreverentes dipsómanos aferrados, demasiadas veces, a la espuria belleza de su propia autodestrucción, real o simbólica.

No quisiera que quedara instalada la idea de que toda la poesía chilena actual es una caótica trama de textualidades de la que poco o nada se podría salvar para efectos de la instalación de imágenes poderosas que ofrezcan, por decirlo de algún modo, soluciones discursivas óptimas para la autorrepresentación estetizada de nuestras experiencias más decidoras en una realidad que se nos da 
de suyo como necesaria pero rara vez satisfactoria. ${ }^{8}$ No obstante, si uno se torna algo receptivo a esta "selva lírica", podría distinguir que las voces, con los debidos matices de cada caso, se tienden a agrupar en campos de afinidades retóricas y de sensibilidad. Uno de éstos es aquél en el que los poetas arremeten contra el lirismo. Digamos, siguiendo un poco a Harold Bloom, arremeten contra aquella manera visionaria de percibir las cosas que amplifica y profundiza una cierta imagen emocional y conceptual gratificantemente "extraña" sobre las realidades materiales y que puede adquirir apariencia de mensaje "profético" o que estimula el pathos contemplativo (Cfr. Cómo leer y por qué, sección sobre la poesía), en beneficio de una hipertrofia de lo metapoético y conceptual; hipertrofia que se correlaciona, además, con un grado de especialización de la escritura que vuelve a la poesía, literalmente, un lujo sólo para quienes pueden acceder a las claves de una especie de enigmática metafísica del lenguaje y/o de los discursos y la cultura en un sentido especializado. Sostengo que esta "especialización" radical de la poesía acontece, a estas alturas de este tan "posmoderno" siglo XXI, menos como formas de (re)escrituras vanguardistas o postvanguardistas, y más como consecuencia sociocultural de la cerrazón del horizonte histórico y político a la hora de imaginar el futuro de la nación de otro modo que no sea la continuación de lo presente; hecho que hace posible y sustentable una manera de imaginar el mundo que halla su expresión depurada en un discurso lírico despojado de verdadera referencialidad, no exento de una actitud de autoflagelación (aunque en el fondo autocomplaciente) con su propia hipertrofia retórica.

Cierto que exagero. Después de todo, ninguna poesía, por hermética que parezca, si es que tiene algún sentido su textualidad, podría renunciar a negociar con las materialidades de la experiencia humana transmutadas en lenguaje. Lo que pretendo es apenas perfilar un campo de escrituras regido por oblicuas actitudes de borradura de la historia en beneficio de un lenguaje que termina trabajando para sí mismo como si la retoricidad de la poesía fuese la condición de realidad que materialmente la origina. Semejante fenómeno lo veo como la consecuencia de una historia de ruptura del sujeto lírico con su propia historicidad y con el lenguaje que la hace narrativamente posible.

Pareciera, pues, más fácil seguir en el clausurado escenario de agonismos existenciales que tomar el camino de una "épica" de victoria sustentada en una relación de identificación del sujeto con su propia colectividad, aunque tal relación esté hoy muy lejos de la posibilidad de erigirse como la voz de los que no tienen voz. La pérdida o desdibujamiento

\footnotetext{
${ }^{8}$ No he leído toda la poesía chilena que se ha producido desde 1990 hasta ahora, y no lo podría hacer aunque me lo propusiera dado el inmenso mar de murmullos líricos que cubren prácticamente todo el territorio.
} 


\section{Sergio Mansilla Torres}

de mundos más allá del efecto fantasmal de realidad de las metáforas es terreno fértil para que la poesía (o una parte de ella por lo menos) le dé la espalda al propósito de ser uña y carne con las experiencias cotidianas en lo que se refiere a proveer al lector de esa visión amplificada y profunda de las cosas a las que alude Bloom y que lo pone frente "a un mundo donde todo lo que mira tiene un aura trascendental" (Cómo leer y por qué, en línea). ${ }^{9}$ Trascendental, agregaría yo, no sólo porque pone al lector ante la afirmación de la divinidad (en términos amplios), de lo metafísico como una presencia de plenitud, sino ${ }^{10}$ porque empuja al lector a la indagación en la experiencia poética de lo efímero, del vacío como potencialidad pura; lo hace ser partícipe de una metafísica de la ausencia que define y hace posible la presencia, siempre transitoria, múltiple, en progreso y en extinción a la vez.

Hay una zona de la poesía chilena en que ésta se hace cargo de la historia; pero de una historia que se vuelve muro infranqueable, solidificado, contra el que la imaginación poética se estrella una y otra vez. Como acontece en la poesía de José Ángel Cuevas, cuyo sujeto lírico hace suya la tragedia de la derrota histórica de esa izquierda chilena que desde los tiempos del Frente Popular soñó con un socialismo concebido literalmente como el fin de la lucha de clases (el fin de la historia, entonces, en el sentido más radical imaginable), poesía que sin darle la espalda a la historia la convierte en hieráticas ruinas, terreno perfecto para que prosperen las "flores del mal". La derrota se convierte en una suerte de venero desde donde brotan incontenibles las aguas de la amargura, del escepticismo, de la carencia de finalidad afirmativa del devenir (no por nada Cuevas cultiva la imagen de "ex-poeta"); amargura, no obstante, matizada por una cáustica ironía que pone sí en evidencia que ante la derrota de los sueños colectivos no caben esteticismos parnasianos. ${ }^{11}$

\footnotetext{
${ }^{9}$ Invito al lector a revisar El placer de los demás, de Pablo Azócar, Premio Consejo Nacional del Libro y La Lectura 2008. Es un libro cuyo registro de escritura es una mezcla de estilo y actitud beatnik (aunque sin el desgarrador lirismo de un Gimsberg, por ejemplo) con alucinantes yuxtaposiciones de referencias culturales al mundo del arte y la literatura y de los mass media y a situaciones decadentes de la vida urbana. El tono general es más o menos antipoético, aunque sin llegar a la irrisión radical de Parra. Es, en mi opinión, un ejemplo de un tipo de poesía que ha hecho de la historia y la memoria un desjerarquizado espectáculo de objetos y sujetos varios. La realidad primaria de las cosas se diluye precisamente en las "tramas de mercado".

${ }^{10}$ Y quizás sea esto lo que distingue a la mejor poesía que se está escribiendo por estos días en Chile.

${ }^{11}$ Cfr., por ejemplo, Poesía de la Comisión Liquidadora y Restaurant (sic) Chile de José Ángel Cuevas. Dice Raúl Zurita de la poesía de Cuevas: "La ex-poesía nos muestra (...) los despojos vivos de una enorme claudicación que los reflectores del discurso del poder no quieren mostrar" (102). En rigor, toda la poesía ("ex-poesía") de Cuevas es una elegía airada por la muerte de ese pueblo proletario chileno que, alguna vez, tuvo a las puertas de la revolución socialista, convertido hoy en tristes despojos que patéticamente se niegan a morir.
} 
La "ex-poesía" de Cuevas proporciona coordenadas para ver la historia como "ex-historia": un acontecer en el que nada acontece salvo la reiteración interminable de los despojos, restos de una fiesta terminada hace tiempo pero que se niega a borrarse del todo, insistiendo en una especie de memoria de lo que no fue ni será nunca. No es el "fin de la historia" en el sentido celebratorio de quienes, después de la caída del muro de Berlín, auguraron con alborozo que el planeta entero se volvería un gran cronotopos en el que libremente el mercado dictaría las reglas de la libertad de producir y de consumir, elevada ésta a condición definitoria del sujeto moderno: un sujeto emprendedor, dispuesto siempre a dar vuelta la página de la historia, o sea, a reprimir/olvidar el pasado. Hablamos de una "ex-historia" como un estado de cosas agotado y sin visos de una recomposición que vuelva a instalar una cierta direccionalidad teleológica en su devenir. Su formulación discursiva, en el campo poético, suele tomar la forma de una memoria elegíaca de realidades opresivas que dan paso a ficcionalizaciones alegóricas que insisten en el derrumbe de una cierta historia (que pudo ser real en algún grado) de plenitud y que, por lo mismo, proyectan reiteradas imágenes de pérdida y de compensación imaginaria de la pérdida. El libro El cementerio más hermoso de Chile (2008) de Christian Formoso, va en esta dirección: territorialmente situado en Punta Arenas, el cementerio de esta ciudad se torna vasto símbolo del poder omnipresente de la muerte en un Chile falsamente vivo detrás de la utilería deslumbrante de la modernidad consumista. Por largos pasajes, Formoso sigue de cerca la estrategia retórica de Edgard Lee Masters en su Antología de Spoon River al otorgar voz a los muertos para que desde sus particulares historias, ya imposibles de cambiar, clausuradas para siempre, elaboren una visión caleidoscópica del derrumbe y de las muchas caras de la derrota. "Lo distintivo del Magallanes urbano, dirá Formoso, lo que nos hace parte distinta del país, es su cementerio: la presencia de la muerte y sus particulares vestigios" (345). El "patetismo de este mito local" (Formoso, 345) halla su contraparte en la imagen de los buques "Malbourgh" y "Esperanza" con sus velas desplegadas, dispuestos al naufragio pero también a henchirse "del viento de nuestros sueños" (347). Vasta metonimia del Chile postdictadura (la expresión la usa el propio Formoso), cementerio hermoso que ha venido a estetizar (y obliterar) las tragedias de tantas vidas truncadas por exterminios antiguos y recientes. La poesía, en este escenario, es denuncia, homenaje a los olvidados, expresión de contra derrota, triunfo de la imaginación poética sobre la inmensa muerte de la historia. Victoria pírrica, sin embargo, si se tiene en cuenta que, en definitiva, se trata sólo de imaginación: la muerte y sus vestigios no pueden ser realmente desalojados de la historia por la sola fuerza de la poesía; es más, si los vestigios son 


\section{Sergio Mansilla Torres}

hermosos, como el cementerio de Punta Arenas, la estética funciona a favor de la muerte. ${ }^{12}$

En una orilla a veces contraria, a veces paralela a estas líneas de escritura que se arman como alegatos contra sí mismas y/o a favor de mundos clausurados, se perfila aquel sector de la poesía chilena que centralmente halla sus fuentes de referencialidad y de retórica en las raíces culturales de la tríada yo-nosotros-otros. En este campo de registros líricos, las distintas formas de retoricidad que concurren a la hora de la conformación de la escritura, siempre historizada y territorializada, valen como una manera de hacer que la violencia de la realidad destile, desde la heterogeneidad de las voces y sujetos, su insoportable peso sobre la conciencia del lector/oyente. La poesía, inscrita en esta "dominante escritural" - expresión tan cara a los análisis culturales del postmodernismo de Fredric Jameson - en general, trabaja en función de asegurar una forma de comunicación que no suspenda la transparencia de los signos, sin menoscabo de la natural opacidad del lenguaje de la poesía, en términos de garantizar que ésta no se vuelva un fin en sí misma, sino un medio para leer/escribir de una manera "fuerte" (Bloom dixit) una cierta historia que necesita ser expropiada desde las marcas culturales definitorias del yo-nosotros-otros. Se trata, por cierto, de una poesía situada en un horizonte políticamente comprometido con la memoria cultural.

Poetas como Delia Domínguez, Clemente Riedemann, Elicura Chihuailaf o Jaime Huenún, por encima de sus singularidades y diferencias estéticas e ideológicas, convergen en un denominador común: sus sujetos líricos se configuran como un campo de voces múltiples, de manera que lo que puede parecer, a primera vista, fragmentación y fisuras del yo es, en estos poetas, el modo en que el sujeto lírico acontece como una heterogeneidad discursiva (que tributa un proceso de (re)construcción y resignificación cultural); sujeto que al hablar y dejar hablar a otros da paso a polifonías que deconstruyen y construyen identidad. Aquí la lírica se torna "épica" de una cierta intrahistoria de derrota y triunfo a la vez (aunque lo uno y lo otro se entremezclen a menudo al punto de que sus límites se tornen vagos y difusos). Como fuere, la poesía de las memorias culturales, por más autoflagelante que parezca, no podría ser lo que es si no sustentara afirmativamente una cierta visión política de las identidades y de su(s) historia(s) que la poesía se encarga

\footnotetext{
${ }^{12}$ No es casual que Formoso en el texto final de El cementerio más hermoso de Chile aluda a Milton Friedman: el "milagro chileno" del que habló Friedman para referirse a los resultados de la transformación económica del país emprendida por la dictadura de Pinochet en los primeros años de su gobierno. Formoso lo imagina como versión tardía de Kooch en Magallanes, divinidad tehuelche que dio origen al mundo rompiendo en llanto ( $C f r$. Formoso, 2008:345). Aquí, entonces, la memoria cultural se la invoca para confirmar que no hay un antes distinto al presente ni el hoy será diferente del futuro, por lo menos, en lo que a los estropicios de Tánatos se refiere.
} 
de instalar como denuncia y reclamo, por un lado, y, por otro, como afirmación y fortalecimiento de una subjetividad cuya realidad ontológica no puede entenderse si no es en el seno de alguna cultura situada, además, en reales territorios de la geografía y la memoria de los cuales la poesía se vuelve testimonio.

La llamada poesía indígena, por ejemplo, es tal no sólo porque incluya referentes culturalmente propios del mundo indígena. Lo es porque, pudiendo o no la escritura referirse a realidades socioculturales indígenas, se la profiere desde un "punto de hablada" que la torna performance discursiva de un sujeto(s) subalterno que batalla por desmontar su subalternidad movilizando, desde una subjetividad personal, la memoria cultural colectiva, fundada en una conciencia de la diferencia etnocultural que cuestiona, cuando menos, el estatuto de la civilización occidental. La conciencia de la diferencia es, aquí, dispositivo de subversión contra la legitimidad de aquellos discursos que, desde el poder de la nación, han construido y naturalizado una memoria a favor de la borradura del otro. La poesía de las memorias culturales asume una explícita función política en un período en que el campo político ha dejado de ser patrimonio de los partidos (el desprestigio de éstos llega a ser hoy grotesco) y su fuerza, si la tiene, no deriva ya de ideologías totalizantes que proclamen explicar y transformar toda la historia para ajustarla a un relato utópico tan perfecto y vasto que clausure la historia; función política que halla su concreción en un recurrente viaje a las memorias culturales e históricas más profundas, más obliteradas, de aquella comunidad de sujetos sintientes de la que el poeta forma parte. Hablo, pues, de autores cuyas acciones creadoras en el campo de la escritura poética se orientan al desmontaje de estereotipos que naturalizan relaciones de poderes coloniales y postcoloniales. Ni la nación en el sentido en que la describe Renan (1882), ni "el pastel entero de la historia" (Linh, 1983), ni la reafirmación irrestricta de un yo expandido, plenamente confiado en el sí mismo que controla y despliega un discurso "iluminador" acerca de las cosas son, en rigor, tópicos constitutivos de estas poéticas. Sí lo son las miserias de un lenguaje que de pronto se queda corto ante la tarea de reescribir/releer la memoria íntima y a la vez cultural-política construida a punta de retazos de recuerdos y de olvidos entremezclados, difusos muchas veces pero que, de un modo u otro, instalan versiones y subversiones de las realidades e irrealidades de la memoria, de la historia, de nosotros y los otros. ${ }^{13}$

\footnotetext{
${ }^{13}$ No ha de deducirse, sin embargo, que la poesía de las memorias culturales es cualitativamente mejor que aquélla cuyo registro está más cerca de alguna cierta forma de metalingüismo, o de esa especie de neoconceptismo con frecuencia abstruso y que tiende a conformarse como una trama alegórica de subjetividades clausuradas sobre sí mismas. Nada de eso. Esta última es o puede
} 


\section{Sergio Mansilla Torres}

¿Qué poesía puede producir una sociedad en extremo privatizada, que presiona sin tregua a su población para integrarse competitivamente a una modernidad que exige cada vez estar un paso más adelante que el otro? ¿Qué imaginación emerge cuando la "caída de los grandes relatos" se vuelve, digamos, desencanto general con la vieja política de partidos y/o pérdida del valor "civilizador" y educativo de la literatura, tanto que en la escuela básica y media ha sido casi erradicada?

Un síntoma del adelgazamiento de aquel espesor cultural que en su momento hizo posible la emergencia de poetas como Mistral, Huidobro, Neruda, de Rokha, Díaz Casanueva, Rojas, hasta Nicanor Parra, es el debilitamiento de la confianza en el sí mismo y su reemplazo por voces más o menos afásicas, minusválidas (Linh dixit) o restringidas a la intimidad minimalista de un yo (como el de Teillier, por ejemplo) que busca armonía en escenarios cotidianos, pequeños, lejos de la grandiosidad metafísica o política. Así, lo que parece escritura vanguardista en los años 70 y 80 del siglo pasado (Juan Luis Martínez, el Zurita de Purgatorio, Rodrigo Lira) bien puede ser interpretado como el último estertor de aquel yo, estilo Canto a mí mismo de Wihtman, sólo que ahora asumiendo hasta los tuétanos el fracaso de la empresa de contar toda historia con esa voz que destilaba fe inquebrantable en el poder civilizador de la poesía. Y, en este contexto, la balanza se termina inclinando más hacia una poesía que instala la idea de que indagar en el modo de hablar de la realidad sería más realidad que la realidad misma de las cosas materiales de las que se habla, o, más extremo aún, lo metadiscursivo y conceptual sería la única realidad digna de poetizar. $\mathrm{O}$ bien se inclina hacia aquella poesía que estetiza la enfermedad o la autodestrucción, incluso física, como si la imaginación quedase perpetuamente atrapada en la derrota. En este escenario, Veneno de escorpión azul (2007) de Gonzalo Millán, por ejemplo, más allá de ser un estremecedor testimonio lírico de un enfermo aquejado de un cáncer terminal, podría verse, también, como síntoma de la imposibilidad de cierta poesía chilena de no ser sino documento de una historia (vista como) inmodificable, historia que apenas deja espacio para el estertor de un sujeto que, además, ha hecho de la derrota y de la autodestrucción, real o simbólica, la fuente y referencia de su imaginación poética.

ser una poesía tan válida como cualquier otra. Lo que quiero enfatizar es la pertinencia del esfuerzo por leer en los varios lenguajes de la actual poesía chilena los subtextos también varios de una historia que abruma por la pérdida de sus horizontes orientadores, salvo aquél que legitima y estimula un mercantilismo desbocado cuyas evanescentes promesas de bienestar y desarrollo para la mayoría de la población son como las manzanas de Tántalo. 


\section{¿Para qué poesía en tiempos de desigualdad?}

\section{A MANERA DE CONCLUSIÓN: POESÍA Y CRÍTICA DE LA POESÍA}

Después de 19 años vengo a coincidir a medias con Eduardo Llanos. En lo que va del siglo XXI la poesía chilena tiene, sin duda, muchas voces. Tal vez, más que nunca en la historia, si uno considera el mar de poemas que circulan por los medios electrónicos ¿Cuántas de estas voces, sin embargo - hasta ahora, al menos - constituyen referentes obligados en el concierto de la poesía continental, voces que no sean las de los viejos tercios de los años 1960 o anteriores? Por otra parte ¿Cuántos autores, que no sean los "grandes poetas" pre 1973, han podido (o han querido) salir de los estrechos límites del pequeño mundo literario local o nacional y proyectarse como voces que lleguen a ser patrimonio necesario del gran público en lengua castellana? No sé si la poesía chilena actual sea en general de menor peso específico que la que se escribía por los años de 1960, como lo sugiere Llanos Melussa; pero, sí, me parece que la poesía de este Chile ferozmente neoliberal en que vivimos, de este insaciable Leviatán que viene creciendo desde fines de los años 70, no ha generado condiciones socioliterarias que favorezcan la cultura de la evaluación cualitativa - que tendría que ser ejercida con extremo rigor crítico- de las muchas escrituras que campean libertinamente en el ruedo de la poesía chilena actual, descontando lo mucho o poco que se haga en centros académicos especializados. El efecto resultante es una desjerarquización que no contribuye a cartografiar, con razonable rigor, quién es quién en la poesía chilena del Bicentenario. ${ }^{14}$

El punto en que sí coincido con Llanos es aquel que dice relación con lo que subraya como característico de la poesía de Jorge Teillier: "la autenticidad del esfuerzo por superar la escisión poesía-vida" (13), y que bien podría ser criterio para identificar puntos altos en la poesía chilena de hoy. En efecto, creo que la mejor poesía es aquella que se configura como esfuerzo sostenido, contra viento y marea, por hacer que la invención poética no se reduzca a un artificio retórico que adelgace la experiencia y la memoria de las materialidades del mundo en beneficio de una cierta inflación de lenguaje que termine convirtiendo la poesía más en acertijo semiótico que en genuino lirismo. Digamos, poesía orientada hacia la concreción de relatos /representaciones de subjetividades que intermitentemente se hacen, deshacen

\footnotetext{
${ }^{14}$ No se trata de construir un ranking de poetas. Me refiero a cartografiar la densidad semántica de las poéticas puestas en un horizonte de historicidad cultural, social y, si viene al caso, territorial, además de situarlas en una cierta tradición(es) de la poesía moderna internacional. Es lamentable el desconocimiento que el público chileno común tiene de la poesía de su país, incluso de las figuras tutelares como Mistral y Neruda, hecho que viene a reforzar el divorcio entre la comunidad de los poetas y sus potenciales lectores. Romper el divorcio es tarea de los propios poetas, pero, sobre todo, es tarea del aparato educacional y comunicacional de la nación.
} 


\section{Sergio Mansilla Torres}

y rehacen en el proceso mismo de ser y estar en la intrahistoria del mundo de las experiencias que poseen valor intersubjetivo. Así, por ejemplo, si hay algo que la poesía etnocultural ha aportado al vasto paisaje de la poesía chilena moderna es, precisamente, la autenticidad del esfuerzo por superar la escisión poesía-vida en el sentido de superar escisiones como yo-colectividad, olvidomemoria histórica, mundos íntimos-mundos socioculturales, categorías que se despliegan en temporalidades que sobrepasan de lejos los límites de las vidas personales. No es, pues, casual que la figura de Teillier sea a menudo invocada por diversos poetas del sur profundo chileno, indígenas o no, a la hora de perfilar sus preferencias de escritura y sensibilidad. ${ }^{15}$ Se hace claro que la poesía, en el período del "capitalismo tardío", es más un lugar de protección y fortalecimiento de los mundos subjetivos que un "arma cargada de futuro" que dé paso a transformaciones propiamente política de una sociedad determinada.

"Luego de lo que pasó en el campo de Auschwitz es cosa barbárica escribir un poema, y este hecho corroe incluso el conocimiento que dice por qué se ha hecho hoy imposible escribir poesía", sentenció Adorno hace ya medio siglo (1962:11). Sus palabras hablan más de la necesidad de poner a tono el lenguaje de la poesía con una realidad que sobrepasó todo lo decible que de la imposibilidad de escribir poemas en sentido literal. La poesía chilena a su manera es todavía una "barbaridad" si la leemos en correlación con el horror de una historia cuyas consecuencias, hábilmente blanqueadas en el campo político, afectan las posibilidades mismas de la imaginación literaria hasta los días de hoy, y, sobre todo, afectan las posibilidades de construir un sólido tinglado crítico. Me atrevería a decir que esa pluralidad escritural, así como la debilidad de la crítica evaluativa y política de la que adolece el campo textual de la poesía de nuestro país, es un síntoma revelador no de lo imposible pero sí de lo difícil que ha sido y todavía es escribir poemas en Chile y leerlos contra una historia que dinamitó la tradición de esa poesía "comprometida" que se sustentaba en la convicción de que a la patria inevitablemente le esperaba un "futuro esplendor", por más lejano que éste sea, y al poeta le estaba reservada la tarea de anunciar y ayudar a construir ese

\footnotetext{
${ }^{15}$ En rigor, Teillier es, por lo menos en Chile, un poeta paradigmático para cualquier escritura que haga de la memoria territorializada su materia formante; no sólo del sur chileno, desde luego. Teillier es importante para muchos poetas chilenos del siglo XXI no por lo lárico, en realidad. Quiero decir, no por esa especie de nostalgia enfermiza por un cronotopos que, idealizadamente, sugiere cuán amable habría sido la modernidad provinciana de las primeras décadas del siglo XX imbricada con la infancia verdadera del poeta. Si hay algo vigente de la poesía de Teillier para la poesía chilena en tiempos de desigualdad, es su genuino empeño por hacer de la poesía un lugar textual donde la historia se vuelve densa, cargada de memorias que revelan cuán descompuesto está nuestro presente y cuán poco útil es, al fin, la poesía para torcerle el rumbo a la historia.
} 


\section{¿Para qué poesía en tiempos de desigualdad?}

futuro. Poesía que da vuelta la página de la historia y que se vuelve sobre su vacío y opacidad lingüística, tratando de extraer sentido de la cerrazón del sentido, o bien poesía que vuelve obsesivamente a las pasadas páginas de la historia y juega más a la transparencia del signo que a su opacidad: he aquí los puntos límites del vasto campo de la poesía chilena actual todavía, estimo, atrapada en la urgencia de deglutir nuestro propio Auschwitz.

\section{Universidad Austral de Chile* \\ Facultad de Filosofía y Humanidades \\ Instituto de Lingüística y Literatura \\ Casilla 567, Valdivia (Chile) \\ changuitad@gmail.com}

\section{BIBLIOGRAFÍA}

ADORNO, Theodor. "La crítica de la cultura y la sociedad", en Prismas. La crítica de la cultura y la sociedad. Trad. Manuel Sacristán. Barcelona: Ariel, 1962:1-11.

AZÓCAR, Pablo. El placer de los demás. Santiago: Cuarto Propio, 2008.

BLOOM, Harold. Cómo leer y por qué. Trad. Marcelo Cohen: Bogotá: Norma, 2000. Versión digital en http://www.scribd.com/doc/7101221/Harold-Bloom-ComoLeer-Y-Por-Que.

CÁRCAMO-HUECHANTE, Luis. Tramas de mercado: imaginación económica, cultura pública y literatura en el Chile de fines del siglo veinte. Santiago: Cuarto Propio, 2007.

CUEVAS, José Ángel. Restaurant Chile. Antología. Santiago: La Calabaza del Diablo, 2005.

CUEVAS, José Ángel. Poesía de la Comisión Liquidadora. Santiago: LOM, 1997.

ESPAÑA, Aristóteles. (Ed.) Generación NN. Punta Arenas: La Pata de Liebre, 1993.

FORMOSO, Christian. El cementerio más hermoso de Chile. Santiago: Cuarto Propio, 2008.

FOSTER, Hal. "Contra el pluralismo". Trad. Desiderio Navarro. Criterios. La Habana, 2007. Versión digital en http://www.criterios.es/masalla.htm (14-10-2009).

GRUPO AMISTAD POR UN MUNDO MEJOR. Poesía de Villa Francia. Anidarás en el bosque de las aves que somos. Libertad con nuestras propias voces. Santiago: Mosquito Comunicaciones, 2008.

HEANEY, Seamus. “Opiniones de Seamus Heaney”. Desde la república de la conciencia y otros poemas. Edición digital de Aquiles Julián. En: http://www.scribd.com/doc/14116809/DESDE-LA-REPUBLICA-DE-LACONCIENCIA-Y-OTROS-POEMAS-POR-SEAMUS-HEANEY [16-10 2009].

LEE MASTERS, Edgard. Antología de Spoon River. (Ed.) Y trad. Jesús López Pacheco. Madrid: Cátedra, 1993.

LIHN, Enrique. Porque escribí. Antología poética. Eduardo Llanos Melussa. (Ed.) Santiago: F.C.E., 1995.

LLANOS MELUSSA, Eduardo. "Jorge Teillier, poeta fronterizo". Los dominios perdidos, de Jorge Teillier. Erwin Díaz. (Ed.) México: F.C.E., 2001:9-15. (Primera edic. 1992). 


\section{Sergio Mansilla Torres}

MANSILLA, Sergio. "Esa manera oblicua y dolida de ver las cosas (poesía del sur de Chile: 1975-1990)", Acta Literaria 19, 1994: 87-100.

MILLÁN, Gonzalo. Veneno de escorpión azul. Diario de vida y de muerte. Edición de María Inés Zaldívar y Andrés Braithwaite. Santiago: Universidad Diego Portales, 2007.

RENAN, Ernest. “¿Qué es una nación?”. Versión digital en: www.cholonautas.edu.pe/modulo/upload/4renan.pdf. (2- 12- 2009).

SERRANO, Bruno. (Ed.) Poesía prisionera. Escritura de cinco mujeres encarceladas. Santiago: Literatura Alternativa, 1988.

ZURITA, Raúl. "La ex-poesía y la muerte de la palabra pueblo". Restaurant Chile. Antología, de José Ángel Cuevas. Santiago: La Calabaza del Diablo, 2005:99102. 